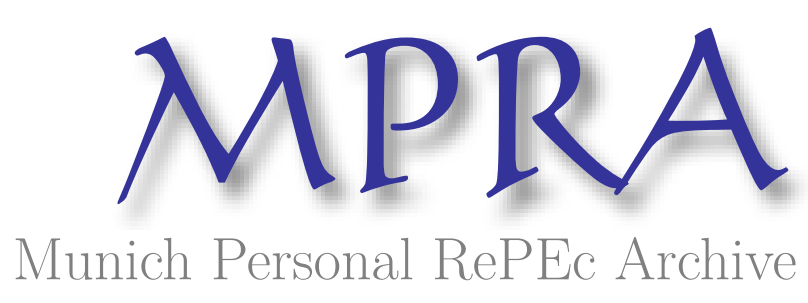

\title{
On the Private Provision of Fiat Currency
}

Berentsen, Aleksander

University of Basel

20 May 2005

Online at https://mpra.ub.uni-muenchen.de/36601/

MPRA Paper No. 36601, posted 30 Dec 2015 08:27 UTC 


\title{
On the Private Provision of Fiat Currency*
}

\author{
Aleksander Berentsen \\ Economics Departement, University of Basel, Switzerland
}

May 20, 2005

\begin{abstract}
This paper considers whether fiat money can be provided by a revenue-maximizing monopolist in an environment where money is essential. Two questions arise concerning the private supply of money: Is it feasible and is it optimal? Concerning the feasibility question, I show that the revenue-maximizing policy is time-consistent if the trading history of the issuer is public information and if money demanders respond to the revelation of defection by playing autarky. Concerning the optimality question, the model suggests that any private organization of the market for fiat currency is suboptimal.
\end{abstract}

Keywords: Time Consistency, Private Money, Search Equilibrium

*In preparing this paper I have benefitted from the comments of Ernst Baltensperger, Martin Hellwig, Guillaume Rochteau, Christopher Waller, Randall Wright and numerous seminar participants. I would also like to thank two anonymous referees and the editor for their very helpful comments. The Swiss National Science Foundation provided financial support. An early version of the paper has circulated under the title "Time-Consistent Private Supply of Outside Paper Money." The author can be contacted at aleksander.berentsen@unibas.ch. 


\section{Introduction}

This paper considers whether fiat money can be provided by a revenue-maximizing monopolist in an environment where money is essential. ${ }^{1}$ Two questions arise concerning the private supply of money: Is it feasible and is it optimal? Concerning the feasibility question, I show that the revenue-maximizing policy is time-consistent if the trading history of the issuer is public information and if money demanders respond to the revelation of defection by playing autarky. Concerning the optimality question, the model suggests that any private organization of the market for fiat currency is suboptimal.

The existence of a monetary equilibrium relies on two features that rule out the timeinconsistency problem: public knowledge of the monopolist's trading history and the existence of punishment strategies that credibly eliminate any future profits of the monopolist if executed. Public knowledge of the issuer's trading history is needed to trigger the punishment strategies if the monopolist deviates from the announced policy. The credibility of the punishment strategies guarantees that it is optimal to use them if the monopolist deviates. The notion that the market can discipline private issuers of fiat currency goes back at least to von Hayek (1976, S. 30) who conjectured that "the slightest suspicion that the issuer was abusing his position when issuing money would lead to a depreciation of its value and would at once drive him out of business. It would make him lose what might be an extremely profitable kind of business."

Thus, as suggested by von Hayek (1976), punishment strategies effectively eliminate the time-inconsistency problem. The equilibrium allocation, however, is suboptimal. The reason is that the first-best allocation requires a deflation which is not consistent with

\footnotetext{
${ }^{1}$ By essential I mean that the use of money expands the set of allocations (Kocherlakota (1998) and Wallace (2001)).
} 
positive profits once the initial stock of money is sold since only positive inflation rates generate the expected profits that make the monopolist willing to adhere to his announced sequence of money supplies.

The monetary equilibrium is characterized as follows: Initially, the monopolist announces the entire sequence of future money supplies and then offers to exchange the initial stock of money for real commodities. Agents accept the initial offer because there is no record, as yet, about the monopolist's past play. In each subsequent period, each agent accepts monetary exchanges (goods for money) from other agents and from the monopolist if and only if the monopolist has not deviated from the announced money supply sequence. Thus, if any deviation occurs, each agent refuses to produce for money today and, in fact, in the future. For each agent it is optimal to respond to the revelation of defection by playing autarky if all other agents respond likewise. Accordingly, the monopolist cannot gain by defection, and, therefore, accepting money in the initial period is a best response.

The model of this paper is based on Shi's $(1997,1999)$ random-matching model with divisible money and divisible real commodities. In Shi's model, the money supply is exogenously given; one contribution of this paper, therefore, is to endogenize the supply of money in the random-matching model with divisible money. The paper is related to several papers that study the private supply of money. Random-matching models include Cavalcanti, Erosa and Temzelides (1999), Ritter (1995), Williamson (1999) and Martin and Schreft (2003). They all study environments with indivisible money and an exogenous upper bound on individual money holdings. I dispense with these assumptions and allow agents to carry any non-negative amount of fully divisible money. Nonrandom matching models include Calvo (1978), Klein (1975), and Taub (1985).

Because of their treatment of the time-inconsistency problem, the models of Cavalcanti 
and Wallace (1999a) and Ritter (1995) are of special relevance for this paper. Cavalcanti and Wallace (1999a) assume that trading histories of bankers, who issue distinguishable inside monies, are public knowledge, and they show that this knowledge is sufficient to rule out the time-inconsistency problem. They derive the incentive-feasible allocation that maximizes the nonbanking sector's welfare and show that this allocation requires note issue and redemption by the bankers. In Ritter's (1995) model a subset of the population belongs to a coalition that issues fiat money. The sequence of money supplies is chosen to maximize the coalition members' discounted utility from trading with nonmembers. He shows that the coalition is able to promise credibly to limit the issue of money if the coalition's involvement in the economy is sufficiently large and if its members are sufficiently patient.

The rest of the paper is organized as follows: In Section 2 an adapted version of Shi's (1997, 1999) model is presented; Section 3 considers the monopolist's revenue-maximizing sequence of money supplies when binding money supply announcements are feasible and when they are not feasible. Section 4 discusses the results and some extensions, and Section 5 concludes.

\section{Demand}

Money demand arises in the search-theoretic model of monetary exchange where money is used to alleviate the double coincidence of real wants problem. The model builds on Shi $(1997,1999)$, who extended the search-theoretic approach developed by Kiyotaki and Wright $(1991,1993)$ to allow for divisible money and divisible goods. ${ }^{2}$ While in Shi's model

\footnotetext{
${ }^{2}$ Lagos and Wright (2005) propose an alternative framework to incorporate fully divisible money in the search-theoretic approach to monetary economics. The relation between Shi's and Lagos and Wright's approach is discussed in Berentsen and Rocheteau (2003). How both frameworks relate to the first-
} 
the supply of money is exogenously given, this paper considers the supply decision of a revenue-maximizing monopolist. Before discussing the monopolist's supply decision, let me describe Shi's model. There are $H>2$ types of households. Each type consists of a large number of households with measure $1 / H$. An arbitrary household of type $h \in H$ is referred to as household $h$. Decision variables of household $h$ are denoted by lower-case letters. Capital-case letters denote other households' variables, which are taken as given by household $h$. Each household type is specialized in consumption and production as follows: a household of type $h$ produces commodity $h+1$ and consumes commodity $h(\bmod H)$, for $h=1, . ., H$.

Households cannot commit to future actions, and each household's trading history with other households is private information to the household. Because $H>2$, these assumptions rule out any barter exchange for optimizing agents. The only storable object is a perfectly divisible and intrinsically useless object called money.

Each household consists of a continuum of members normalized to one, who carry out different tasks but regard the household's utility as the common objective. Household members are grouped into money holders (buyers) and producers (sellers), each performing one task at a time. A buyer attempts to exchange money for consumption goods, and a seller attempts to produce goods for money. The fraction of buyers is given by the exogenous constant $B .^{3}$ Time is discrete and household members are randomly matched in pairs in each period where the probability that a seller meets an appropriate buyer (a buyer of household $h+1$ who holds money) is $z B$, and the probability that a buyer meets an appropriate seller is $z(1-B)$ where $z \equiv 1 / H$.

generation search models of indivisible money is analyzed in Berentsen and Rocheteau (2002).

${ }^{3}$ Shi $(1997,1999)$ also allows households to choose the fraction of buyers $B$ in each period. To focus on the central issue of the paper, the problem of an optimal money supply sequence is examined when the fraction of buyers is given. 
At the beginning of each period, the household has $m_{t}$ units of money and chooses a uniform consumption level for each member, $c_{t}$, and the next period's money stock, $m_{t+1}$. The household then divides evenly the money stock among its buyers so that each buyer holds $m_{t} / B$ units of money in a match and specifies the trading strategies for its members. After this, the agents are matched and carry out their exchanges according to the described strategies. Thereafter, members bring back their receipts of goods and money, and each member consumes $c_{t}$ units of goods. At the end of a period, the household receives money transfer $\tau_{t}$ and carries the stock $m_{t+1}$ to $t+1$.

Household utility in a period is given by $u(c)-k y$ where $c$ is the quantity of goods consumed, $y$ is the quantity of goods produced, and $k$ is the marginal cost of production where $k>0$. The function $u$ is defined on $[0, \infty)$, is increasing, three times differentiable, and satisfies $u(0)=0, u^{\prime \prime}<0, u^{\prime}(0)=\infty$ and $2 u^{\prime \prime}(c)+c u^{\prime \prime \prime}(c)<0{ }^{4}$ The household discounts future utility with the discount factor $\beta \in(0,1)$.

Denote $\omega_{t}$ the household's period $t+1$ marginal value of money, discounted to period t. For the sake of simplicity, assume that a buyer who meets an appropriate seller makes a take-it-or-leave-it offer to the seller, and the seller accepts it if made no worse off by accepting. The take-it-or-leave-it offer is the pair $\left(q_{t}, x_{t}\right)$, where $q_{t}$ is the quantity of goods produced by the seller for $x_{t}$ units of money. If the seller accepts the offer, the acquired money balances $x_{t}$ will add to the household's money balances at the beginning of period $t+1$, whose value is $\Omega_{t} x_{t}$. The cost associated with this trade is $k q_{t}$ and the seller accepts the offer if $x_{t} \Omega_{t} \geq k q_{t}$. Thus, any optimal offer satisfies

$$
x_{t} \Omega_{t}=k q_{t}
$$

\footnotetext{
${ }^{4}$ The last assumption guarantees that the first-order condition of the monopolist represents a maximum. It is satisfied, for example, by the utility function $u(c)=c^{\alpha}$, where $0<\alpha<1$.
} 
Because a buyer cannot exchange more money than he has, the offer $\left(q_{t}, x_{t}\right)$ satisfies

$$
x_{t} \leq m_{t} / B
$$

A household's trading strategy consists of the pair $\left(q_{t}, x_{t}\right)$ for each buyer, and the numbers $\pi_{t} \in\{0,1\}$ and $\pi_{t}^{m} \in\{0,1\}$ for each seller. Given the offer $\left(Q_{t}, X_{t}\right)$ by a buyer of another household, the seller decides either to accept $\left(\pi_{t}=1\right)$ or to reject $\left(\pi_{t}=0\right)$. Sellers also receive offers to produce for money from the monopolist (details are specified in the next section), which the sellers accept $\left(\pi_{t}^{m}=1\right)$ or reject $\left(\pi_{t}^{m}=0\right)$. For each period, the household chooses $\left(m_{t+1}, c_{t}, q_{t}, x_{t}\right)$, and $\left(\pi_{t}, \pi_{t}^{m}\right)$ to solve the following maximizing problem:

$$
\max \sum_{t=0}^{\infty} \beta^{t}\left[u\left(c_{t}\right)-\phi_{t}\right]
$$

subject to (1), (2), and

$$
\begin{aligned}
c_{t} & \leq z(1-B) B \Pi_{t} q_{t} \\
\phi_{t} & =z(1-B) B k \pi_{t} Q_{t}+f\left(\pi_{t}^{m} \tau_{t}\right) \\
m_{t+1}-m_{t} & \leq \pi_{t}^{m} \tau_{t}+z(1-B) B \pi_{t} X_{t}-z(1-B) B \Pi_{t} x_{t} \\
m_{t+1} & \geq 0
\end{aligned}
$$

The variables taken as given in the above problem are the state variable $m_{t}$ and other households' choices. Inequality (4) specifies the household's consumption. With probability $z(1-B)$, a buyer meets an appropriate seller and he receives $\Pi_{t} q_{t}$ units of goods. Because $B$ is the measure of buyers per household, $z(1-B) B \Pi_{t} q_{t}$ represents the total quantity of consumption goods acquired by the household. Equation (5) specifies the household's cost of producing for other households and for the issuer. The first term on the righthand side is the household's cost of producing for other households. A seller meets with probability $z B$ an appropriate buyer and produces $\pi_{t} Q_{t}$ units of goods at cost $k \pi_{t} Q_{t}$. 
As the fraction of sellers is $(1-B)$, total cost for the household is $z(1-B) B k \pi_{t} Q_{t}$. The second term specifies the household's cost of producing for the monopolist. If the monopolist sells $\pi_{t}^{m} \tau_{t}$ units of additional currency to the household, total cost to the household is $f\left(\pi_{t}^{m} \tau_{t}\right)$ (details are specified in the next section). In Shi's $(1997,1999)$ models, households receive additional money through lump-sum transfers. Accordingly in Shi's models $f\left(\pi_{t}^{m} \tau_{t}\right)=0$ and $\pi_{t}^{m}=1$. Inequality (6) specifies the law of motion of the household's money balance. The first term on the right-hand side specifies the additional currency the household acquires from the monopolist, the second term specifies sellers' money receipts when selling goods, and the third term specifies buyers' expenses when exchanging money for goods.

To simplify the problem, note the following: First, inequality (6) must hold with equality if money is valued in the future. Second, inequality (4) holds with equality, given the household's preferences; therefore, $c_{t}$ can be substituted by the equality of (4) throughout the problem. Third, by the equation (1), $x_{t}$ can be substituted throughout the problem. Fourth, the other households' choices $\left(Q_{t}, X_{t}\right)$ satisfy a condition similar to equation (1). Thus, a household gets a nonnegative surplus when selling; therefore, $\pi_{t}=\Pi_{t}=1$ in a monetary equilibrium. ${ }^{5}$

After substituting $c_{t}, x_{t}$, and $\pi_{t}$, the remaining choice is $q_{t}$. Let $\mu_{t}$ be the shadow price of inequality (2), expressed in period- $t$ utility. Then, if $u^{\prime}\left(c_{t}\right)=\frac{\partial u\left(c_{t}\right)}{\partial c_{t}}$, the envelope condition for $m_{t}$ and the first order condition for $q_{t}$ are as follows:

$$
\begin{aligned}
\omega_{t} & =\beta\left[\omega_{t+1}+z(1-B) \mu_{t+1}\right] \\
u^{\prime}\left(c_{t}\right) & =\frac{k\left(\omega_{t}+\mu_{t}\right)}{\Omega_{t}}
\end{aligned}
$$

Equation (7) is the optimality condition for $m_{t}$. It states that the marginal cost of ac-

\footnotetext{
${ }^{5}$ There exists a nonmonetary equilibrium with $\pi_{t}=\Pi_{t}=0$.
} 
quiring money today, $\omega_{t}$, equals the discounted marginal benefit of money tomorrow, $\omega_{t+1}$, plus the discounted marginal benefit of relaxing future cash constraints, $z(1-B) \mu_{t+1}$. Equation (8) states that, for a buyer in a desirable match, the marginal utility of consumption must equal the opportunity cost of the amount of money that must be paid to acquire additional goods. To buy another unit of a good, the buyer must give up $\frac{k}{\Omega_{t}}$ units of money (see eq. (1)). Increasing the monetary payment has two costs to the buyer. He gives up the future value of money $\omega_{t}$ and he faces a tighter constraint (2). Together, $\omega_{t}$ and $\mu_{t}$ measure the marginal cost of obtaining a larger quantity of goods in exchange.

Definition 1 A symmetric monetary equilibrium is a sequence of household's choices $\left(m_{t+1}, c_{t}, q_{t}, x_{t}, \pi_{t}\right)_{t=0}^{\infty}$, the implied shadow prices $\left(\omega_{t}, \mu_{t}\right)_{t=0}^{\infty}$, and other households' choices such that

(i) given other households' choices and shadow prices, each household's choices solve the dynamic programming problem (3);

(ii) choices and shadow prices are the same across households;

(iii) $\tau_{t}=m_{t+1}-m_{t}=(\gamma-1) m_{t}, \gamma>0$.

The first part of the definition requires that each household choose a best response against other household choices. Part (ii) states that the equilibrium is a symmetric solution to such best response correspondences, and part (iii) specifies the exogenously given sequence of money supplies, where $\gamma$ is the gross growth rate of money. In a symmetric equilibrium, lower-case variables equal capital-case variables and are replaced by the corresponding capital-case variables. Then, equations (7) and (8) give a single condition, which the monopolist takes into account when choosing the sequence of money supplies:

$$
\Omega_{t}=\beta \Omega_{t+1}\left[1+z(1-B) \frac{u^{\prime}\left(c_{t+1}\right)-k}{k}\right]
$$


If the gross growth rate of money is constant (see Shi 1997, 1999), the equilibrium quantity produced in a single-coincidence meeting is the value of $Q$ that solves

$$
u^{\prime}[z(1-B) B Q]=k\left[\frac{z(1-B)+\gamma / \beta-1}{z(1-B)}\right] .
$$

Denote this value by $Q^{*}$. Then in a symmetric monetary equilibrium, in each period the buyers make the offer $\left(Q^{*}, X_{t}^{*}\right)$, which the sellers accept. In this model, money is neutral as the nominal quantity of money does not affect real production. However, money is not superneutral. This can be seen from equation (10), which implies that $Q^{*}$ is strictly decreasing in $\gamma$.

\section{Supply}

Money is offered to the households by a single issuer. The issuer consists of a large number of members called money agents, and the number of members is such that the issuer can assign one member to each seller of each household. Members' preferences for goods are symmetric among goods and satisfy $u\left(Q^{m}\right)=Q^{m}$, where $Q^{m}$ is the quantity of goods consumed. Money agents cannot produce real commodities; rather, they have the technology that permits them to create at no cost, a divisible, durable, and intrinsically useless object called money. Since they cannot produce real commodities no note redemption by the monopolist is feasible. As in Ritter (1995), the sequence of money supplies is chosen to maximize the organization's joint discounted utility from trading with nonmembers. Because all money agents are identical and their preferences are linear, this is equal to maximizing the expected discounted utility of a representative money agent. ${ }^{6}$

\footnotetext{
${ }^{6}$ The linear utility for the members of the monopolist household implies that the monopolist has no interest to smooth consumption across time. This creates a strong incentive to overissue money today since the marginal utility is not decreasing. Therefore, if my punishment strategies can discipline the monopolist for a linear utility function, they should also work for a strictly concave utility function.
} 
Binding announcements I first consider the utility-maximizing policy when binding announcements are feasible and, thereafter, I consider nonbinding supply announcements. In each case each period is divided into two subperiods. At the beginning of a period, household members meet randomly in pairs and carry out their trades; at the end of a period, the issuer assigns one member to each seller of each household, and each money agent makes the same take-it-or-leave-it offer $\left(Q_{t}^{m}, X_{t}^{m}\right)$, where $Q_{t}^{m}$ is the quantity of goods produced by the seller for $X_{t}^{m}$ units of money. In the initial period, $t=0$, the monopolist announces the entire sequence of offers $\left\{Q_{t}^{m}, X_{t}^{m}\right\}_{t=0}^{\infty}$ and households choose their trading strategies. After the announcement the money agents sell the initial stock of nominal balances to the households through the offers $\left(Q_{0}^{m}, X_{0}^{m}\right)$.

Given a sequence of offers $\left\{Q_{t}^{m}, X_{t}^{m}\right\}_{t=0}^{\infty}$, the expected discounted lifetime utility of a money agent is $\sum_{t=0}^{\infty} \beta^{t} Q_{t}^{m}$. The analysis is simplified by noting that controlling this sequence is equivalent to controlling the sequence of nominal money supplies $\left\{M_{t}\right\}_{t=1}^{\infty} \cdot{ }^{7}$ To see this, note that if a seller accepts the offer $\left(Q_{t}^{m}, X_{t}^{m}\right)$, the acquired money balances $X_{t}^{m}$ will add to the household's money balances at the beginning of period $t+1$, whose real value is $\Omega_{t} X_{t}^{m}$. The cost associated with this trade is $k Q_{t}^{m}$, and the household's surplus is $\Omega_{t} X_{t}^{m}-k Q_{t}^{m}$. The seller accepts the offer if $\Omega_{t} X_{t}^{m} \geq k Q_{t}^{m}$. Thus, any optimal offer satisfies

$$
\Omega_{t} X_{t}^{m}=k Q_{t}^{m}
$$

Given (11), the lifetime utility of a money agent can be expressed as $\sum_{t=0}^{\infty} k^{-1} \beta^{t} \Omega_{t} X_{t}^{m}$. If money agents offer $\left(Q_{t}^{m}, X_{t}^{m}\right)$, households acquire $M_{t+1}-M_{t}=(1-B) X_{t}^{m}$ units of

\footnotetext{
${ }^{7}$ Throughout the paper I focus on symmetric equilibria where all households are treated equaly that is, each household receives the same take-it-or-leave-it offers. Note, however, deviations from such a policy may involve asymmetric offers. Given this, if all households are treated symmetrically, the control of the sequence of take-it-or-leave-it offers is equivalent to the control of the sequence of money supplies $\left\{M_{t}\right\}_{t=1}^{\infty}$, which in equilibrium equals the sequence of the stocks of money held by each household, $\left\{m_{t}\right\}_{t=1}^{\infty}$.
} 
additional currency in each period. Accordingly, the monopolist's problem (thereafter called $P M)$ is to choose the sequence of nominal money supplies $\left\{M_{t}\right\}_{t=1}^{\infty}$ that maximizes

$$
\sum_{t=0}^{\infty} k^{-1}(1-B)^{-1} \beta^{t}\left(M_{t+1}-M_{t}\right) \Omega_{t}
$$

subject to the demand conditions (9), and

$$
M_{t+1}-M_{t} \geq 0
$$

Several comments are in order here. First, inequality (13) expresses the fact that money agents cannot redeem money. Second, it also highlights a key difference between public and private issuers: Private issuers have no ability to tax agents' money balances whereas public issuers, at least in principal, have that power. This is why a private issuer cannot run the Friedman rule, which would require $\gamma=\beta<1$. Third, the sequence of real revenues $\left\{\left(M_{t+1}-M_{t}\right) \Omega_{t}\right\}_{t=0}^{\infty}$ is homogenous of degree zero in the sequence $\left\{M_{t}\right\}_{t=1}^{\infty}$. Thus, a proportional change in the money supply sequence has no effect on the sequence of real revenues. This is a consequence of the neutrality of money, which is a property of Shi's $(1997,1999)$ divisible money model used here. Third, and related to the previous point, if a sequence $\left\{M_{t}\right\}_{t=1}^{\infty}$ solves $P M$, any sequence $\left\{\lambda M_{t}\right\}_{t=1}^{\infty}, \lambda>0$, is a solution to $P M$.

Finally, $P M$ can be further simplified by noting that the control of $\left\{M_{t}\right\}_{t=1}^{\infty}$ is equivalent to the control of the sequence of households' consumption $\left\{c_{t}\right\}_{t=0}^{\infty}$. To see this, multiply equation (9) by $M_{t+1}$ to get

$$
M_{t+1} \Omega_{t}=\beta M_{t+1} \Omega_{t+1}\left[1+z(1-B) \frac{u^{\prime}\left(c_{t+1}\right)-k}{k}\right]
$$

and substitute this expression into the monopolist's objective function. This and equation (1) yield the modified objective 


$$
\sum_{t=0}^{\infty} \frac{\beta^{t}}{z(1-B)^{2}}\left\{\beta c_{t+1}\left[1+z(1-B) \frac{u^{\prime}\left(c_{t+1}\right)-k}{k}\right]-c_{t}\right\}
$$

Maximization of (14) with respect to consumption $c_{t}$ yields the first-order conditions

$$
\begin{aligned}
c_{0} & =0 \\
u^{\prime}\left(c_{t}\right)+c_{t} u^{\prime \prime}\left(c_{t}\right) & =k, t>0
\end{aligned}
$$

According to equation (15), in the initial period, the monopolist destroys the value of any old currency $\left(c_{0}=0\right)$ and issues a new money. ${ }^{8}$ Thereafter, by equation (16), the issuer earns seigniorage income by taxing (by selling additional units of money) the outstanding stock of money by a constant gross growth rate of money, $\bar{\gamma}$. To derive $\bar{\gamma}$, denote $\bar{c}_{t}$ the value of $c_{t}$ that solves equation (16) and note that (16) implies that $\bar{c}_{t}=\bar{c}$ is constant. If $\bar{c}_{t}$ is constant, the households' first-order condition (9) implies that $\gamma_{t}=\bar{\gamma}$ where $\bar{\gamma}$ is the value of $\gamma$ that solves

$$
u^{\prime}(\bar{c})=k\left[\frac{z(1-B)+\gamma / \beta-1}{z(1-B)}\right] .
$$

Next, note from (16) that $u^{\prime}(\bar{c})>k$, which from (17) implies that $\bar{\gamma}>\beta$. Shi (1997) shows that the Friedman rule (i.e., $\gamma=\beta$ ) maximizes the utility of the households. Thus, not surprisingly, the monopolist's desire for seigniorage income induces him to have too much inflation from the households' point of view. For certain parameter values, the solutions to the first-order conditions (16) and equation (17) involve deflation, which violates condition (13). ${ }^{9}$ Proposition 1 , which takes this condition into account, characterizes the revenuemaximizing policy of the monopolist when binding announcements are feasible.

\footnotetext{
${ }^{8}$ Without a medium of exchange $\left(M_{0}=0\right)$ households do not consume in the initial period because they cannot trade. Although $M_{0}=0$ is the maintained assumption, I have set up a more general maximization problem which allows for $M_{0}>0$. If $M_{0}>0$, the optimal policy is to make the initial stock of money worthless (e.g., by announcing to sell an infinite amount of the old money) and then to issue a new money.

${ }^{9}$ Deflation is more likely the flatter the curvature of the utility function. Note further that $\bar{\gamma}$ is increasing in $\beta$, in the single coincidence probability $z$, and in the fraction of sellers, $1-B$.
} 
Proposition 1 There exists a critical value $\beta_{1}$, defined in the proof, such that the following is true: If $\beta \geq \beta_{1}$, the sequence $\left\{c_{0}^{*}=0, c_{t}^{*}=\bar{c}\right\}_{t=1}^{\infty}$ solves PM where $\bar{c}$ is the value of $c$ that solves (16). If $\beta<\beta_{1}, P M$ is solved by the sequence $\left\{c_{0}^{*}=0, c_{t}^{*}=\widetilde{c}\right\}_{t=1}^{\infty}$ where $\widetilde{c}$ is defined in the proof. In terms of the associated sequence of money supplies if $\beta \geq \beta_{1}$, the sequence $\left\{M_{t}^{*}=\bar{\gamma}^{t-1} M_{1}\right\}_{t=1}^{\infty}$ solves PM where $\bar{\gamma}$ is the value of $\gamma$ that solves (17) and $M_{1}>0$ is some arbitrarily chosen initial quantity of nominal money. If $\beta<\beta_{1}$, the sequence $\left\{M_{t}^{*}=M_{1}\right\}_{t=1}^{\infty}$ solves $P M$ where $M_{1}>0$ is again some arbitrarily chosen initial quantity of nominal money.

According to Proposition 1 , the sequence of money supplies $\left\{M_{t}^{*}\right\}_{t=1}^{\infty}$ maximizes the expected lifetime utilities of money agents. From this sequence, the optimal sequence of take-it-or-leave-it offers $\left\{Q_{t}^{m *}, X_{t}^{m *}\right\}_{t=0}^{\infty}$ can be derived. The optimal sequence of money offered to the sellers in a match is

$$
\left\{X_{0}^{m *}=\frac{M_{1}^{*}}{1-B}, X_{t}^{m *}=\frac{\left(\gamma^{*}-1\right) M_{t}^{*}}{1-B}\right\}_{t=1}^{\infty}
$$

where $\gamma^{*}=\bar{\gamma}$ if $\beta \geq \beta_{1}$ and $\gamma^{*}=1$ if $\beta<\beta_{1}$ and the optimal sequence of real commodities demanded from the sellers is

$$
\left\{Q_{0}^{m *}=\frac{c^{*} \gamma^{*}}{z(1-B)^{2}}, Q_{t}^{m *}=\frac{c^{*}\left(\gamma^{*}-1\right)}{z(1-B)^{2}}\right\}_{t=1}^{\infty}
$$

where $c^{*}=\bar{c}$ if $\beta \geq \beta_{1}$ and $c^{*}=\widetilde{c}$ if $\beta<\beta_{1}$. To derive the optimal sequence of quantities $\left\{Q_{t}^{m *}\right\}_{t=0}^{\infty}$, note that equation (1) implies that the sequence of shadow prices associated with the sequence $\left\{M_{t}^{*}\right\}_{t=1}^{\infty}$ is $\left\{\Omega_{0}^{*}=\frac{k c^{*} \gamma^{*}}{z(1-B) M_{1}^{*}}, \Omega_{t}^{*}=\frac{k c^{*}}{z(1-B) M_{t}^{*}}\right\}_{t=1}^{\infty}$. From this use (11) to derive the sequence $\left\{Q_{t}^{m *}\right\}_{t=0}^{\infty}$.

Nonbinding announcements The time-inconsistency problem (possibly) associated with the optimal sequences $\left\{M_{t}^{*}\right\}_{t=1}^{\infty}$ is most clear if the optimal policy calls for a constant money supply. With zero money growth, money agents consume $Q_{0}^{m *}$ units of real 
commodities initially and nothing thereafter. From the perspective of the initial period, this may be a good policy because zero inflation increases consumption today. From the perspective of the following period, initial consumption no longer enters the monopolist's considerations and the monopolist would like to sell additional money. Because of the monopolist's desire to deviate from the announced policy, many economists (e.g., Calvo (1978), Taub (1985), Hellwig (1985), and White (1999)) conclude that when no binding announcement are feasible, revenue-maximizing policies are time-inconsistent and this rules out any unregulated private organization of a market for fiat currency (Hellwig $1985 \mathrm{p}$. $581) \cdot{ }^{10}$

The problem with this conclusion is that without specifying the demand for money after each possible history of the game, the question of whether the announced sequence of money supplies $\left\{M_{t}^{*}\right\}_{t=1}^{\infty}$ is time-consistent or time-inconsistent cannot be answered. Knowledge of the demand for money after each possible history is crucial because this determines the monopolist's expected stream of future revenues after each possible deviation. ${ }^{11}$ To construct a monetary equilibrium, however, it is not necessary to describe the entire game in detail; it is sufficient to show that a credible punishment strategy exists which eliminate the monopolist's desire to deviate from the announced policy.

For this purpose, denote $\Psi^{*}=\left\{Q_{t}^{m *}, X_{t}^{m *}\right\}_{t=0}^{\infty}$ the announced optimal sequence of

\footnotetext{
${ }^{10}$ Calvo (1978) was first to point out the time-inconsistency problem of a revenue-maximizing money supply sequence. The optimal solution $\left\{M_{t}^{*}\right\}_{t=1}^{\infty}$ is time-consistent if for any $t_{0}, n$, and $t \geq t_{0}+n$, $M_{t}^{*}\left(t_{0}+n\right)=M_{t}^{*}\left(t_{0}\right)$. That is, the optimal solution is time-consistent if what is optimal to do in period $t$ from the vantage point of $t_{0}$ is also optimal when the point of departure is $t_{0}+n$ (see Calvo (1978) for this definition).

${ }^{11}$ It is not surprising that the monopolist's desire to deviate depends on her expectation of the demand for money following any deviation. However, to my knowledge, with the exception of Cavalcanti and Wallace (1999a and 1999b), the demand for money after out-of-equilibrium moves has not been studied before. The details of the demand for money are also important to determine quantitively how much the time-inconsistency problem accounts for periods of high inflation in countries with poorly designed monetary institutions.
} 
take-it-or-leave-it offers defined by equations (18) and (19). To construct punishment strategies, assume that the monopolist's trading history is public information and let $\eta_{t}$ denote the monopolist's trading history, where $\eta_{t}$ contains each take-it-or-leave-it offer the monopolist has made up to time $t-1$. Furthermore, let $\eta_{t}^{*}$ denote the history of offers associated with the announced policy $\Psi^{*}$ and consider the history-dependent strategy $\Gamma_{h}^{*}=$ $\left(m_{t+1}^{*}, c_{t}^{*}, q_{t}^{*}, x_{t}^{*}, \pi_{t}^{*}, \pi_{t}^{m *}\right)_{t=0}^{\infty}$ where $m_{t+1}^{*}, c_{t}^{*}, q_{t}^{*}$, and $x_{t}^{*}$ solve the representative household's maximization problem described in Section 2, given the announced policy $\Psi^{*}$, and $\pi_{t}^{*}$ and $\pi_{t}^{m *}$ are defined as follows:

$$
\begin{aligned}
\pi_{t}^{*} & =\left\{\begin{array}{l}
1 \text { if } \eta_{t}=\eta_{t}^{*} \text { and } X_{t} \omega_{t} \geq k Q_{t} \\
0 \text { otherwise }
\end{array}\right. \\
\pi_{t}^{m *} & =\left\{\begin{array}{l}
1 \text { if } \eta_{t}=\eta_{t}^{*} \text { and }\left\{Q_{t}^{m}, X_{t}^{m}\right\}=\left\{Q_{t}^{m *}, X_{t}^{m *}\right\} \\
0 \text { otherwise }
\end{array}\right.
\end{aligned}
$$

The acceptance rule (20) specifies a seller's behavior when matched with a buyer who makes the take-it-or-leave-it offer $\left\{Q_{t}, X_{t}\right\}$. The seller accepts the offer if the monopolist's trading history, $\eta_{t}$, coincides with $\eta_{t}^{*}$, and if the surplus $X_{t} \omega_{t}-k Q_{t}$ is nonnegative. The acceptance rule (21) specifies a seller's behavior when matched with a money agent who makes the take-it-or-leave-it offer $\left\{Q_{t}^{m}, X_{t}^{m}\right\}$. Again, the seller accepts the offer if the monopolist's trading history coincides with the announced plan, and if the monopolist makes the equilibrium offer $\left\{Q_{t}^{m *}, X_{t}^{m *}\right\}$. To proceed let $\Gamma^{*}$ denote the strategy profile consisting of each household's strategy $\Gamma_{h}^{*}$ and let $\left\langle\Psi^{*}, \Gamma^{*}\right\rangle$ denote the strategy profile consisting of the sequence of take-it-or-leave-it-offers $\Psi^{*}$ and $\Gamma^{*} \cdot{ }^{12}$

Proposition 2 The strategy profile $\left\langle\Psi^{*}, \Gamma^{*}\right\rangle$ is a subgame perfect monetary equilibrium.

\footnotetext{
${ }^{12}$ Note that $\left\langle\Psi^{*}, \Gamma^{*}\right\rangle$ is not a strategy profile in a strict sense because it does not specify the monopolist's and households' actions if they observe an out-of-equilibrium move of a single household. However, because the measure of a household is zero, I ignore deviations of households and focus on out-of-equilibrium moves of the monopolist.
} 
Five comments are required here. First, any deviation by the monopolist triggers complete autarky. That is, every seller in every subsequent meeting refuses to produce for money. For each household it is optimal to respond to the revelation of defection by playing autarky if all other agents respond likewise. Second, if $\beta>\beta_{1}$, it is strictly optimal for the monopolist to adhere to the announced policy because she can sell additional money in each period. If $\beta \leq \beta_{1}$, it is weakly optimal to adhere to the announced policy because the monopolist is indifferent between adhering to the announced plan and any deviation. Third, if the monopolist makes a deviating offer that yields a strictly positive surplus to the seller's household at today's value of money, it is optimal for the seller not to accept the offer because of the household's belief that he cannot buy anything with the additional money in the future. Fourth, household must revert to complete autarky whenever the monopolist deviates. Households cannot just stop trading with the monopolist because each household would have an incentive to deviate from such a punishment strategy by accepting additional money from the monopolist. Fifth, in a more realistic information structure, the monopolist's past play would be revealed with a random delay. For example, one could assume that each period the public record of the monopolist's past transactions is updated with probability $\rho$ and that there is no updating with probability $1-\rho$. This implies that the average updating lag is $1 / \rho$ periods. Kocherlakota and Wallace (1998) use such an information structure in a model where the past play of each agent is recorded with a random lag.

\section{Discussion and extensions}

Since Barro and Gordon (1983) the central banking literature has extensively used punishment mechanisms to prevent public issuers of fiat currency from overissuing. In the 
central banking literature the market's "punishment" is to increase its inflation expectation should the central bank overissue currency. In my model, the market simply refuses to accept the currency should the private issuer deviate from the announced plan. One might argue that such punishment strategies are unrealistic. However, there is no obvious reason why punishment strategies should work for public issuers of fiat currency but not for a private monopolist. Moreover, for many developing countries non-acceptability is the more relevant threat even for public issuers of currency since agents can switch to an alternative foreign currency such as the dollar.

There is little in the Barro and Gordon model that requires the central bank to be a public issuer of currency. The only reason is that it cares about social welfare as opposed to private welfare as the monopolist in my model. However, in the performance contract models of Walsh (1995) and Fratianni et al. (1997) the central bank also cares about its private welfare and not just social welfare. ${ }^{13}$ Performance contracts are written such that maximizing the central bank's self-interest also maximizes social welfare. One could in principal adapt the model of the current paper along the same lines by introducing an initial stage where the households offer the money issuing household an incentive contract to prevent overissue.

The model shows that, as suggested by von Hayek (1976), punishment strategies effectively eliminate the time-inconsistency problem. Nevertheless, it also suggests that any private organization of the market for fiat currency is suboptimal. The reason is that optimality requires a deflation which is not consistent with positive profits once the initial stock of money is sold since only positive inflation rates generate the expected profits that

\footnotetext{
${ }^{13}$ Similarly, the "conservative" central bank literature argues for appointing a central banker who dislikes inflation more than the rest of society. See Waller (1992) for example.
} 
make the monopolist willing to adhere to his announced sequence of money supplies. ${ }^{14}$ It is interesting to relate this result to the Suffolk Bank of New England (1825-58). The Suffolk bank created a well-functioning interbank payment system and some authors (e.g. Colomiris and Kahn (1996)) concluded from this example that unregulated competition in the provision of payments services can produce an efficient payments system. However, Rolnick et al. (1998) have questioned this view by showing that the Suffolk Bank earned extraordinary profits which in my model is inconsistent with an efficient allocation of resources.

This result questions von Hayek's (1976) argument that currency competition is socially desirable. The reason is that there is a trade-off. On the one hand, if the currencies are distinguishable, competition lowers the average rate of inflation. ${ }^{15}$ On the other hand, more competition lowers future profits which reduces the issuers' incentives to adhere to their announced sequences of money supplies.

The stability of the monetary system is another issue that arises with the private provision of currency. In an environment without uncertainty about the behavior of the monopolist punishment strategies work very effectively to sustain the monetary equilibrium because the slightest suspicion that an issuer is abusing his position will trigger autarky. In an environment with uncertainty such suspicions can arise when they are false. In such environments the monetary system is very fragile since it can collapse without real cause as in the bank-run literature where a run on a bank can occur even when the bank is perfectly

\footnotetext{
${ }^{14} \mathrm{~A}$ public issuer of fiat currency can implement the first-best allocation by following the Friedman rule. This policy, however, requires that the public issuer can extract fiat currency from the economy. Note also that the Friedman rule only improves the allocation relative to the best allocation consistent with a monetary equilibrium in this model, if the cost of the tax system required to collect the currency is sufficiently low.

${ }^{15}$ Here I assume that the competing issuers are involved in Cournot competition. In this case there exist a monetary equilibrium where an increase in the number of issuers decreases the average rate of inflation.
} 
sound.

Finally, the issue arises whether a private issuer would implement stabilization policies that maximize society's welfare in an economy which is hit by aggregate real shocks. If not, this could be another reason why most economies have opted for a monopolistic public issuer of fiat currency and not a private profit-maximizing one.

\section{Summary}

This paper considers a monopolist's revenue-maximizing supply of fiat currency in a randommatching model with divisible money and divisible real commodities. When binding announcements are feasible, the monopolist's policy is characterized by an initial period where she initiates a currency reform which destroys the value of any old currency, and then issues new money, which she taxes by a constant gross growth rate of money.

The paper shows that even in the absence of binding policy announcements, this revenue-maximizing policy is time-consistent. The time-consistency of the monopolist's policy relies on the public's knowledge of the issuer's trading history and on the existence of a credible punishment strategy. The punishment strategy involves complete autarky that is, each seller in every meeting refuses to produce for money. The punishment is credible because for each household it is optimal to play autarky if all other household respond likewise. 


\section{Appendix}

Proof of Proposition 1: Note, first, that condition (13) is nonbinding if

$$
\left[u^{\prime}(\bar{c})-k\right] z(1-B) \geq k(1-\beta) \beta^{-1}
$$

Next, note that the right-hand side of (22) is strictly decreasing in $\beta$, that the lefthand side does not depend on $\beta$, and that the solution to the second first-order condition is independent of $\beta$. Thus, for any $\bar{c}$ there exists a critical value $\beta_{1}$ such that $\left[u^{\prime}(\bar{c})-k\right] z(1-B)=k\left(1-\beta_{1}\right) \beta_{1}^{-1}$. Therefore, if $\beta \geq \beta_{1}$, inequality (13) is nonbinding and the sequence $\left\{c_{0}^{*}=0, c_{t}^{*}=\bar{c}\right\}_{t=1}^{\infty}$ satisfies the first-order conditions (15) and (16). The second-order condition for a maximum is satisfied because of the assumption $2 u^{\prime \prime}(c)+c u^{\prime \prime \prime}(c)<0$ imposed on the curvature of the utility function. Thus, if $\beta \geq \beta_{1}$, the sequence $\left\{c_{0}^{*}=0, c_{t}^{*}=\bar{c}\right\}_{t=1}^{\infty}$ solves $P M$.

If $\beta<\beta_{1}$, inequality (13) is binding. As the first-order condition (16) is strictly decreasing in $c$, the optimal policy in this situation is $c_{t}=\widetilde{c}$, for $t>0$, where $\widetilde{c}$ is the value of $c$ that satisfies (22) at equality. Thus, if $\beta<\beta_{1}$, the sequence $\left\{c_{0}^{*}=0, c_{t}^{*}=\widetilde{c}\right\}_{t=1}^{\infty}$ solves $P M$. The associated sequences of money supplies $\left\{M_{t}^{*}=\bar{\gamma}^{t-1} M_{1}\right\}_{t=1}^{\infty}$ and $\left\{M_{t}^{*}=M_{1}\right\}_{t=1}^{\infty}$, respectively, are implied by equation (17). This completes the proof.

Proof of Proposition 2: By applying the one-shot deviation principle, I first show that the strategy profile $\left\langle\Psi^{*}, \Gamma^{*}\right\rangle$ is a Nash equilibrium. First, consider any period $t>0$. If $\beta>\beta_{1}$, the best response of the monopolist against $\Gamma^{*}$ is $\left\{Q_{t}^{m}, X_{t}^{m}\right\}=\left\{Q_{t}^{m *}, X_{t}^{m *}\right\}$ because $\left\{Q_{t}^{m}, X_{t}^{m}\right\} \neq\left\{Q_{t}^{m *}, X_{t}^{m *}\right\}$ yields zero revenue, not only in period $t$, but in any of the following periods, and $\left\{Q_{t}^{m}, X_{t}^{m}\right\}=\left\{Q_{t}^{m *}, X_{t}^{m *}\right\}$ yields a positive revenue, not only in period $t$, but in any of the subsequent periods. If $\beta \leq \beta_{1}$, it is weakly optimal to chose $\left\{Q_{t}^{m}, X_{t}^{m}\right\}=\left\{Q_{t}^{m *}, X_{t}^{m *}\right\}$ against $\Gamma^{*}$ because any deviation as well as the equilibrium 
strategy yields zero revenue today and in the future. Thus, $\left\{Q_{t}^{m}, X_{t}^{m}\right\}=\left\{Q_{t}^{m *}, X_{t}^{m *}\right\}$, $t>0$, is a best response against $\Gamma^{*}$. Next, consider the best response in some period $t>0$ of the representative household $h$ against the strategy profile $\left\langle\Psi^{*}, \Gamma_{-h}^{*}\right\rangle$ where $\Gamma_{-h}^{*}$ denotes the strategy profile consisting of the equilibrium strategies of all other households. If all other households accept monetary exchanges and the monopolist's strategy is $\Psi^{*}$, then it is a best response to accept money in exchange for real commodities at date $t$. Therefore, neither the monopolist nor the household has a profitable deviation in any period $t>0$. Next, consider the initial period. Given $\Gamma^{*}$, the solution to the monopolist's maximization problem PM implies that $\Psi^{*}$ is a best response against $\Gamma^{*}$ and, by the same reasoning as above, $\Gamma_{h}^{*}$ is a best response against $\left\langle\Psi^{*}, \Gamma_{-h}^{*}\right\rangle$. Thus, I conclude that the strategy profile $\left\langle\Psi^{*}, \Gamma^{*}\right\rangle$ is a Nash equilibrium.

Next, I show that the strategy profile $\left\langle\Psi^{*}, \Gamma^{*}\right\rangle$ is a subgame-perfect Nash equilibrium. While doing so, I focus on out-of-equilibrium moves of the monopolist because the measure of a single household is zero and, therefore, deviations of a single household are irrelevant. Consider any out-of-equilibrium move $\left\{Q_{t}^{m}, X_{t}^{m}\right\} \neq\left\{Q_{t}^{m *}, X_{t}^{m *}\right\}$ at some date $t>0$. If $\left\{Q_{t}^{m}, X_{t}^{m}\right\} \neq\left\{Q_{t}^{m *}, X_{t}^{m *}\right\}$, all households reject money subsequently. Thus, the subgame that starts in the period following this deviation is the autarky equilibrium, and it is well known that the autarky equilibrium is a Nash equilibrium of this subgame, in fact, of any subgame, including the whole game. If other households do not accept money, the best response for household $h$ is not to accept money. Moreover, this best response is independent of the nature of the deviation of the monopolist. 


\section{References}

[1] Barro, Robert J. and David B. Gordon (1983). Rules, Discretion and Reputation in a Model of Monetary Policy. Journal of Monetary Economics, 12, 101-121.

[2] Berentsen, Aleksander and Rocheteau, Guillaume (2002). On the Efficiency of Monetary Exchange: How Divisibility of Money Matters. Journal of Monetary Economics, 49:8, November 2002, 1621-49.

[3] — (2003). On the Friedman Rule in Search Models with Divisible Money. Contributions to Macroeconomics: Vol. 3: No. 1, Article 11.

[4] Calvo, Guillermo, 1978. Optimal Seignorage from Money Creation: An Analysis in Terms of the Optimum Balance of Payment Deficit Problem. Journal of Monetary Economics 4, 503-517.

[5] Cavalcanti, Ricardo, Andres Erosa, and Ted Temzelides, 1999. Private Money and Reserve Management in a Random-Matching Model. Journal of Political Economy.

[6] Cavalcanti, Ricardo and Neil Wallace, 1999a. A Model of Private Banknote Issue. Review of Economic Dynamics 2, $104-136$.

[7] —. 1999b. Inside and Outside Money as Alternative Media of Exchange. Journal of Money, Credit and Banking 31 (3), 443 - 457.

[8] Calomiris, Charles W., and Kahn, Charles M. 1996. The efficiency of self-regulated payments systems: Learning from the Suffolk System. Journal of Money, Credit, and Banking 28 (November, Part 2): $766-97$.

[9] Fratianni, M., J. von Hagen and C. Waller, 1997. Central Banking as a Political Principal-Agent Problem, Economic Inquiry 35, 378-393.

[10] Hellwig, Martin F., 1985. What Do We Know About Currency Competition? Zeitschrift für Wirtschafts- und Sozialwissenschaften 105, 565-88. 
[11] Kiyotaki, Nobuhiro and Randall Wright, 1991. A Contribution to the Pure Theory of Money. Journal of Economic Theory 53, 215-34.

[12] —. 1993. A Search Theoretic Approach to Monetary Economics. American Economic Review 83, 63-77.

[13] Klein, Benjamin, 1974. The Competitive Supply of Money. Journal of Money, Credit and Banking 6 (4), 423 - 453.

[14] Kocherlakota, Narayana, 1998. Money is Memory. Journal of Economic Theory, 81, $232-251$.

[15] Kocherlakota, Narayana and Neil Wallace, 1998. Optimal Allocations with Incomplete Record Keeping and No Commitment. Journal of Economic Theory 81, 272 - 289.

[16] Lagos, R. and R. Wright (2005). A Unified Framework for Monetary Theory and Policy Evaluation. Journal of Political Economy (forthcoming).

[17] Martin, Antoine and Stacey L. Shreft (2003). Currency Competition: A Partial Vindication of Hayek. Working Paper. Federal reserve bank of Kansas City.

[18] Ritter, Joseph, 1995. The Transition from Barter to Fiat Money. American Economic Review 85:1, 134-49.

[19] Rolnick, Arthur J., Bruce D. Smith and Warren E. Weber, 1998. Lessons From a Laissez-Faire Payments System: The Suffolk Banking System (1825-58). Federal Reserve Bank of Minneapolis Quarterly Review Vol. 22, No. 3, Summer 1998, 11-21.

[20] Shi, Shouyong, 1997. A Divisible Search Model of Fiat Money. Econometrica 65, 75102.

[21] — 1999. Search, Inflation, and Capital Accumulation. Journal of Monetary Economics 44 No.1, 81-104.

[22] Taub, Bart, 1985. Private Fiat Money with Many Suppliers. Journal of Monetary Economics 16, 195-208. 
[23] Von Hayek, Friedrich A., 1976. Denationalisation of Money. Institute of Economic Affairs, London. Hobart Paper Special, 70.

[24] Wallace, Neil, 2001. Whither Monetary Economics International Economic Review, $42,847-869$.

[25] Waller, Christopher J., 1992. The Choice of a Conservative Central Banker in a Multisector Economy. American Economic Review, 82(4), 1006-12.

[26] Walsh, Carl E., 1995. Optimal Contracts for Central Bankers. American Economic Review, 85, 150-167.

[27] White, Lawrence H., 1999. The Theory of Monetary Institutions. Blackwell Publishers, Oxford.

[28] Williamson, 1999. Private Money. Journal of Money, Credit and Banking 31 (3), 469 - 491. 